\title{
Teleological explanations in evolution classes: video-based analyses of teaching and learning processes across a seventh-grade teaching unit
}

Helge Gresch ${ }^{*}$ (D)

\begin{abstract}
Background: Students frequently explain evolutionary processes, such as adaptation, in a teleological way. These teleological explanations may involve goal-directedness, purpose, an external designer or the internal needs of individual organisms as causal factors. While many science educators consider teleological bias to be a central obstacle in understanding evolutionary processes, other scholars argue that teleological (and anthropomorphic) formulations may also serve pedagogical aims, e.g., to increase empathy and to relate topics to students' world. Although many empirical studies describe the abundance of students' teleological explanations, little is known about how teachers deal with teleological explanations in the classroom and the relationship between teachers' approach and students' learning processes. Consequently, this study addresses the research question of how a teacher and students situationally address teleology across a teaching unit on evolution.

Results: This article presents a case study on teacher-student interactions within a seventh-grade teaching unit on evolution. Video and audio data from the classroom are complemented with data from a post hoc interview with the teacher. Data are analyzed using the qualitative documentary method. Analyses show that the teaching practice can be described as ambiguous and is characterized by a compatibility of scientific and teleological explanations. This results in the reproduction and enforcement of students' teleological explanations. These aspects of the teaching practice are related to the teaching norms stated in the interview: the norm of motivating students and the norm of transforming teleological explanations into scientifically adequate evolutionary explanations. The results show that in contrast to the interview, these norms cannot be reconciled in teaching practice.

Conclusions: The relationship between teaching norms and teaching practice is discussed in view of norms in the field of biology education, i.e., conceptual development from teleological to evolutionary explanations, and teleology and anthropomorphisms as a means to promote interest. In this light, suggestions for dealing with teleological explanations are elaborated on, focusing on metacognitive approaches. Furthermore, it is argued that videos and transcripts of classroom interactions also provide rich data for the education of preservice teachers and for professional development.
\end{abstract}

Keywords: Evolution, Student conceptions, Conceptual change, Teleology, Anthropomorphism, Classroom interaction, Discourse, Video, Documentary method

*Correspondence: helgegresch@uni-muenster.de

Center for Biology Education, University of Münster, Schlossplatz 34,

48143 Münster, Germany

(c) The Author(s) 2020. This article is licensed under a Creative Commons Attribution 4.0 International License, which permits use, sharing, adaptation, distribution and reproduction in any medium or format, as long as you give appropriate credit to the original author(s) and the source, provide a link to the Creative Commons licence, and indicate if changes were made. The images or other third party material in this article are included in the article's Creative Commons licence, unless indicated otherwise in a credit line to the material. If material is not included in the article's Creative Commons licence and your intended use is not permitted by statutory regulation or exceeds the permitted use, you will need to obtain permission directly from the copyright holder. To view a copy of this licence, visit http://creativeco mmons.org/licenses/by/4.0/. The Creative Commons Public Domain Dedication waiver (http://creativecommons.org/publicdomain/ zero/1.0/) applies to the data made available in this article, unless otherwise stated in a credit line to the data. 


\section{Introduction}

Evolution is undoubtedly of high relevance for biology as a scientific discipline and as a school subject. For students, however, evolutionary processes are difficult to understand because they are largely counterintuitive (Garvin-Doxas and Klymkowsky 2008) and involve many challenging concepts (Tibell and Harms 2017). Explaining evolution requires students to acknowledge random processes such as mutation, the concept of probability, unimaginably large timescales and relationships between multiple organizational levels, ranging from the molecular level of genes to populations and entire ecosystems (Tibell and Harms 2017; cf. Jördens et al. 2016). These concepts are difficult to understand because students have little experience with them in everyday life. Instead, students perceive everyday interactions as goal-directed, intentional and based on internal needs, and they relate these experiences to biological phenomena. Consequently, students come to the classroom with many alternative conceptions; these conceptions can be supportive as a form of prior knowledge on which students can rely, but alternative conceptions can also be an obstacle to understanding the abstract processes of evolution (Evans et al. 2012; Kampourakis and Zogza 2008; Kelemen 2012). Teleological bias has been reported as one central type of student conception, along with anthropomorphisms, essentialist conceptions and use/disuse arguments (see Gregory 2009, for a review). From a constructivist perspective, there is a need to understand learning processes, particularly how student conceptions are related to scientific explanations. While much research has been conducted to understand students' conceptions, more empirical evidence is needed to understand how teachers deal with teleological explanations in the classroom and the resulting learning processes of students. Because of the complexity of classroom interaction and learning processes, which are assumed to take place in the course of a teaching unit, it is important to conduct extensive in-depth analyses regarding the development across an entire unit. For this case study, one-seventh-grade biology course on evolution is purposefully selected from a larger research project (cf. Gresch and Martens 2019) because teleological explanations can be observed throughout the entire unit.

\section{Theoretical background}

Studies in biology education have shown students' abundant use of teleological explanations in different biological contexts and their preference for teleological explanations over causal scientific explanations (Abrams and Southerland 2001; Bartov 1981; Bishop and Anderson 1990; Kelemen 1999; Richardson 1990; Tamir and Zohar 1991; Trommler et al. 2018). Consequently, the frequent use of teleological explanations has been described from different theoretical perspectives as "promiscuous teleology" (Kelemen 1999, 1440), "common misconception" (Gregory 2009, 167) or "widespread cognitive construal" (Coley and Tanner 2012, 210), i.e., an "informal, intuitive way of thinking about the world" (ibid., 210). Lennox and Kampourakis (2013, 421) define a "teleological explanation as one, in which some property, process or entity is explained by appealing to a particular result or consequence that it may bring about". Furthermore, teleological explanations may involve goaldirectedness, purpose, an external designer or internal needs of individual organisms (Bishop and Anderson 1990; Kelemen 2012). Taking into account the intuitive notion of teleology and its origin in everyday social interactions, teleological explanations are also described as "tacit knowledge" (Gresch and Martens 2019, 261; cf. Gresch 2020 in press).

Student explanations of biological phenomena also frequently involve anthropomorphisms, i.e., the "manner of attributing human reasoning to nonhuman beings" (Tamir and Zohar 1991, 58). Explanations of animal behavior, such as a bird's display to attract mates or a plant's preference for a habitat, allow for anthropomorphic explanations (ibid.). In evolution education, explanations such as the notion of intentional adaptations of organisms to deliberately cope with environmental conditions can be both anthropomorphic and teleological. Hence, there is a significant overlap between these two types of conceptions.

In contrast, adequate scientific explanations of evolution are based on the "key concepts of natural selection" (Nehm and Schonfeld 2008, 134). These involve "(1) the causes of phenotypic variation (e.g., mutation, recombination, sexual reproduction); (2) the heritability of phenotypic variation; (3) the reproductive potential of individuals; (4) limited resources and/or carrying capacity; (5) competition or limited survival potential; (6) selective survival based on heritable traits; (7) a change in the distribution of individuals with certain heritable traits." Among these key concepts, variation, heritability and differential survival/selection are considered indispensable and are termed "core concepts of natural selection" (Opfer et al. 2012, 745; cf. Tibell and Harms 2017).

To understand the role of teleological explanations in the biology classroom, it is necessary to investigate possible sources of a teleological understanding with reference to cognitive development and social interaction that students experience in everyday situations. Furthermore, drawing on debates from the philosophy of science and from science education, normative considerations regarding the legitimacy and illegitimacy of different types of teleological explanations need to be discussed. 
Based on these considerations, empirical findings regarding instruction in biology classes will be presented.

Students perceive many types of social interactions in their lives as teleological, which may contribute to teleological bias when explaining biological phenomena. Human behavior, such as going to the refrigerator in order to get a drink, may be experienced as goal-directed, or artifacts may be known as designed and used for a specific purpose; e.g., scissors are made in order to cut paper. The first example refers to human actions, which children may perceive as intentional. Individual needs are satisfied through purposeful actions. In the second example, artificial objects made by human beings are constructed intentionally to fulfill a certain function. Using everyday artifacts and being surrounded by a large number of them may enforce a teleological understanding (Kampourakis 2014). Several research projects have examined the ability of children to distinguish between natural (living and nonliving) objects and artifacts. Most studies have shown that preschool children generally tend to provide teleological explanations for the existence of natural objects as well as artifacts (Kampourakis et al. 2012b; Kelemen 1999; cf. Kampourakis 2014, for a review). While a developmental change can be observed regarding the selectivity of employing teleological explanations only to living and not to non-living natural objects, primary students still explain the traits of living organisms and artifacts in a teleological way (Kampourakis et al. 2012).

Although the tendency to explain biological phenomena teleologically persists until adulthood (Kelemen and Rosse 2009; Kelemen 2012), teleological explanations and their acceptance generally decrease with age. Kelemen (1999) showed that primary school students used more teleological explanations than adults. From 10th to 12th grade, Zohar and Ginossar (1998) observed a trend of fewer teleological and anthropomorphic explanations with higher age and education. Generally, this trend is attributable to either cognitive development or education, but the two factors are often confounded because knowledge from formal education increases with age. Casler and Kelemen (2008) showed that unschooled adults used more teleological explanations than adults after formal education. Consequently, the decrease in teleological bias is not simply a result of cognitive development but a result of formal schooling. Therefore, understanding the learning processes in the classroom is crucial.

Different facets of teleological explanations exist, and their legitimacy in biology education needs to be discussed. Often, teleological bias is considered an obstacle to understanding evolution (Evans et al. 2012; Kampourakis and Zogza 2008; Kelemen 2012). Contrary to the wings of an airplane, which were constructed intentionally, the wings of birds evolved through evolutionary processes, including variation and selection (see Kampourakis 2014, for the analogy between organisms and artifacts). If such a conscious external agent is assumed to be the cause of the evolution of living organisms, this analogy is problematic because natural selection does not involve consciousness. Such external agents may be a personified evolution, a designer or Mother Nature (Kelemen 2012). In addition to including external agents, explanations of evolutionary change include the internal needs of individuals and effort-based adaptation (Bishop and Anderson 1990; Kelemen 2012). While natural selection is clearly legitimate as a scientific explanation, design-based or need-based teleological explanations are deemed problematic for learning evolution (Abrams and Southerland 2001; Bishop and Anderson 1990; Lennox and Kampourakis 2014; Kelemen 2012). In many studies, teleological explanations are contrasted with causal explanations (Casler and Kelemen 2008; Richardson 1990). However, from a philosophy of science perspective, natural selection can also be considered teleological because the function of a specific trait may contribute to the survival and higher fitness of an organism due to selective pressure and is thus the cause for the existence of this trait (Kampourakis 2020; Lennox and Kampourakis 2013). A full review of the philosophical debate, however, is beyond the scope of this empirical article (cf. Lennox and Kampourakis 2013; Ruse 1989; Pittendrigh 1958). Regardless of whether the evolutionary process of natural selection is framed as an ultimate causal explanation (Mayr 1961) or selection-based teleology as one type of causal reasoning (Kampourakis 2020; Lennox and Kampourakis 2013), similar implications can be stated for science education. While external designbased explanations and internal need-based explanations are commonly considered illegitimate in explaining evolution, natural selection is regarded as adequate from a scientific perspective. Therefore, learning progressions aim at reducing inadequate teleological explanations and increasing the frequency of evolutionary explanations in line with the scientific norm (e.g., Bartov 1981; Kampourakis and Zogza 2009).

On the other hand, teleological and anthropomorphic explanations may have pedagogical value because longer explanations can be shortened, and empathy may enhance interest in the subject (Zohar and Ginossar 1998). Additionally, teleological explanations may have heuristic value in science because the observation of functions results in new hypotheses about the underlying causal mechanisms. Therefore, many scientists use teleological formulations "as if [the organisms] were designed" (Boerwinkel et al. 2009, p. 14). In their community of researchers, it is not necessary to fully explain 
the underlying process of natural selection because these processes are shared knowledge (Abrams and Southerland 2001). Consequently, it is important to distinguish between teleological language and teleological understanding (cf. Trommler et al. 2018).

From a normative point of view, many suggestions have been made regarding how to address teleological explanations. Generally, many biology educators suggest differentiating explicitly between problematic teleological explanations and scientific explanations (Bartov 1981; González et al. 2011; Jensen and Finley 1996; Richardson 1990; Trommler et al. 2018). This differentiation is particularly important because students lack the metacognitive ability to distinguish between these two types of explanations (Trommler et al. 2018). Such an approach may include critical reflection on analogies between the construction of artifacts, e.g., airplanes, and the evolution of living organisms, e.g., birds (Kampourakis et al. 2012a). Focusing on conceptual development, educators have argued that teleological explanations can be challenged by confronting students with the existence of traits that do not have a function, such as the wings of ostriches, or nonexistent traits that may fulfill an individual's needs, such as gills in whales (Kampourakis et al. 2012b). Similarly, Zohar and Ginossar (1998) confronted students with conflicting phenomena, such as albino plants, which still bend towards light, or deciduous trees, which keep shedding their leaves in a greenhouse. In contrast to these approaches aiming to reflect upon teleology, some learning materials may provide teleological explanations in an uncritical way, such as teleological instruction in chemistry textbooks (Talanquer 2007) or documentaries on evolution (Aldridge and Dingwall 2003). Despite manifold suggestions to reflect on teleology, the effectiveness of such approaches still needs to be investigated by empirical research.

Compared to the large number of studies with students at different ages (ranging from primary school to undergraduate students), few studies have addressed teleological explanations presented by teachers and the learning processes in the classroom. Nehm and Ridgway (2011) showed that experts (university instructors) rejected many more teleological formulations in a questionnaire (a modified version of Bartov 1978) than novices (undergraduate students). Furthermore, university instructors used hardly any naïve ideas in an open response instrument (ORI, Nehm and Reilly 2007; cf. Bishop and Anderson 1990). Some preservice teachers in the study by Crawford et al. (2005) used alternative explanations for evolution, including teleological explanations. However, novices are not the only individuals who use teleological explanations. In the study by Nehm and Schonfeld (2007), 25\% of in-service teachers provided use/disuse arguments and need-based explanations. Examining actual instruction practices, Betz et al. (2019) showed that instructors used "anthropic" (ibid., p. 1) language (including the subtypes of anthropomorphic and anthropocentric language) in $100 \%$ of the undergraduate biology classes at examined universities, and teleological language was present in $96-98 \%$ of the classes. Overall, anthropic, teleological and essentialist language could be observed in $43-60 \%$ of the content minutes per class session. Regarding teaching practices at high school, Gresch and Martens (2019) showed that some twelfth-grade high school teachers combine teleological and scientifically correct explanations in the classroom. The teachers' teaching habitus is characterized by ambiguity regarding the combination of teleological and scientifically correct explanations, which offers opportunities for students to reproduce teleological explanations. In contrast, teachers with a teaching habitus characterized as polarization evaluated all student answers by distinguishing between correct scientific explanations and incorrect teleological explanations. Students' teleological explanations and notions of conscious external agents and need-based explanations were rejected by both the teacher and other students.

\section{Research questions}

The question of how teachers should deal with teleological and anthropomorphic explanations in the classroom has long been debated. This debate is rooted in different normative assumptions considering such explanations as a type of student conception that needs to be developed or challenged according to the norms of scientifically valid explanations or as a way to increase empathy and interest (Evans et al. 2012; Zohar and Ginossar 1998). While the controversy in the philosophy of science about teleology in evolutionary processes shows sophisticated viewpoints on its legitimacy and illegitimacy, there is still a lack of empirical studies in the field of science education that investigate how teachers deal with teleological explanations in the classroom and students' learning processes. Consequently, in this research project, the overarching research question is the following: how do teachers and students address teleology in evolution classes? Analyzing these classroom interactions involves examining the situational conditions for learning set by the teacher, e.g., the tasks and learning materials, the students' (and teacher's) construction of teleological explanations, and the way the teacher and the students deal with such teleological explanations. This (co-)construction of meaning in the classroom is the main focus of this study.

In a previous article on this project (Gresch and Martens 2019), the interactions of teachers and high school students were analyzed, and different types of relations 
between the teaching habitus and the learning habitus were presented. While the previous article focused on the description of different types of interactions illustrated by one sequence per unit, the aim of this article is to examine and describe interactions across one entire unit in depth. Because learning sequences at school are structured as units by agents in the field, a study on teaching and learning processes needs to focus on the development across a whole unit. Moreover, the complexity of classroom interaction requires in-depth analyses that can best be performed based on a case study.

While the routines of teaching practices can be examined with video analyses, classroom interaction itself does not necessarily reveal the teaching norms or the teacher's rationale in an explicit way. Therefore, it is necessary to investigate how explicitly stated teaching norms on dealing with teleology relate to actual teaching practices. Consequently, the two research questions for this case study are as follows:

1. How do the teacher and the students situationally address teleology across a teaching unit on evolution?

2. How do the teacher's teaching norms and rationale relate to the teaching practices regarding teleology?

\section{Method}

To answer these research questions of the case study, video and audio data from a seventh-grade teaching unit were interpreted. Moreover, a post hoc interview with the teacher was conducted to relate these findings to the explicated teaching norms regarding teleological explanations.

\section{Sample}

In this article, the data of a seventh-grade biology course ${ }^{1}$ are presented as a case study. Overall, ten teaching units from grades 7 to 13 were video-recorded for 4 to 10 periods each $90 \mathrm{~min}$ in duration. In addition, interviews were conducted with most of the teachers. The sampling strategy for this case study was to select for in-depth analyses a unit in which teleological explanations are abundant and reproduced throughout the unit.

A total of 27 students were enrolled in the course included in the case study, and the teacher had been teaching biology for ten years. Concerning the teacher's professional background, he had completed the regular German teacher education program at university; this program includes courses in biology and biology

\footnotetext{
${ }^{1}$ Beethoven grammar school 1 (anonymized school name).
}

education as well as courses in educational science. ${ }^{2}$ In addition, he had participated in the obligatory two-yearlong practical teacher education program, which includes supervised teaching and culminates with the receipt of a state teacher certification.

The school was a public German grammar school (Gymnasium); i.e., the students were high-achieving students. In Germany, approximately 40\% (destatis 2020) of the student population at this age attends this type of grammar school. Among these high-track schools, the school in this case study can be considered a regular school. It was located in a small market town in a rural area in northwest Germany. According to Konnemann et al. (2016), very few students in this area hold creationist beliefs, and most students have positive attitudes towards evolution.

The state's curriculum (Ministerium für Schule und Weiterbildung des Landes Nordrhein-Westfalen 2008) requires teachers to teach an evolution unit in grade 7 or 9. The curriculum content includes the earth's history, time scales, the evolution of vertebrates and human beings, evolutionary mechanisms, and scientific research in the field of evolution. Possible contexts are fossils, changes in living organisms and habitats, and biodiversity as a resource. Therefore, a teaching unit on evolution is obligatory, and the presented unit generally covers the curriculum content. In line with the organization of the curriculum, the students did not have a previous unit on genetics or evolution, but they had 2 years of biology classes prior to grade seven.

\section{Classroom interaction: data collection and analysis}

The course was video-recorded for eight 90 -min periods. In the classroom, two video cameras were installed at opposing corners of the room to cover as many interactions as possible. In addition, five audio recorders were placed on the students' tables to record the students during small group discussions. Relevant sequences were transcribed for interpretation. These sequences for the interpretation process were selected according to two aspects, namely, interactive density and focus of the research interest (Bohnsack 2010), i.e., whether teleological explanations can be observed. For the presentation in the manuscript, passages out of these sequences were selected to illustrate the results of the interpretations.

\footnotetext{
${ }^{2}$ Degrees in biology and biology education involve approximately 75 ECTS for a bachelor's degree plus 25 ECTS for a master's degree. Degrees in educational science involve approximately 20 ECTS each for a bachelor's degree and a master's degree. The number of credit points for this particular teacher was not assessed as part of the study. This study provides the number of credit points at the University of Münster, which is likely to be similar to the teacher's educational background. Although these numbers are considered typical in Germany, they may vary from one university to another.
} 
Analysis of the interactions was performed using the qualitative documentary method (Asbrand and Martens 2018; Bohnsack 2010; cf. Gresch and Martens 2019 for details on the methodological background), which is based on the sociology of knowledge (Mannheim 1952) and systems theory (Luhmann 2002). The interpretations aim at differentiating between the immanent (explicit, literal) and documentary (implicit, tacit) meanings of the interactions. It is generally assumed that both the teacher and the students have incorporated knowledge that can be observed in the interactions but is difficult for them to explicate. Although many actions may be the result of a deliberate planning process, routines and internalized patterns are also based on implicit knowledge (Schön $1983)$, or, as Shulman $(1987,6)$ stated, "teachers themselves have difficulty in articulating what they know and how they know it". This implicit knowledge is also referred to as the "framework of orientation" (Bohnsack $2010,104)$. The aim of the interpretation process is to explicate this implicit knowledge of the teacher and the students by reconstructing the teaching and learning habitus.

Consequently, the method distinguishes between two steps. First, in a formulating interpretation, the immanent meaning of what is said and done is reconstructed by assigning (sub)topics and (sub)actions. This interpretation step represents the perspective of the persons under investigation. Second, a reflecting interpretation is conducted to reconstruct how this is said and done. The aim is to explicate the implicit knowledge underlying the interactions and to describe the frameworks of orientation of the teacher and the students. This approach involves a formal analysis of the functions of the utterances and the relation between them; e.g., the first person makes a proposition of a new framework of orientation, which may be elaborated on or validated by a second person. Interaction units may be antithetical; i.e., the persons discuss different positions but share a common framework of orientation. Such antithetical interactions are concluded in a synthesis. Interaction units may also be complementary, divergent or oppositional; i.e., the persons do not share a common framework of orientation, and the interaction does not resolve in a synthesis. Often, students and teachers do not share the same framework of orientation due to their asymmetric relationship (cf. Asbrand and Martens 2018).

After these separate steps of analysis, which are documented in extensive working papers, the interpretations are then merged and condensed for presentation. To validate that the implicit knowledge structures were adequately reconstructed, homologies and differences are reconstructed within the same teaching units and across different teaching units. Through these comparative analyses (cf. Glaser and Strauss 1967), types in the form of generalized rules are developed. A further measure of validation is the discussion of the interpretations in two different research groups who work with the documentary method.

\section{Interview: data collection and interpretation}

In addition to the video and audio data from the teaching unit, a post hoc interview was conducted with the teacher approximately 2 months after the end of the teaching unit. The stimulus for the interview was a set of four different student explanations taken from the classroom transcripts, which were given to the teacher at the beginning of the interview. These quotes from the classroom transcripts were chosen to represent a variety of authentic student answers, some of them with teleological formulations (see transcript in results section). All student quotes relate well to the three sequences of the teaching unit presented in this article, though they are not always the same. The teacher was asked to read the quotes aloud and to talk about them. This open stimulus was chosen to allow the teacher to choose the focus of the interview after an open question. After $14 \mathrm{~min}$, the interviewer asked follow-up questions, picking up words and phrases the teacher had used and asking him to elaborate on them; e.g., after the teacher had explained aspects of his rationale, the interviewer asked him to elaborate on them. In this phase of the interview, however, the interviewer gave no additional input. Moreover, to avoid an exam-like situation and a judgmental atmosphere between the teacher and the researcher, he did not ask the teacher to justify the decisions he had made in the teaching unit.

As in the analyses of the teacher-student interactions, the documentary method allows for differentiating between explicit knowledge (what is said and done, i.e., the literal or immanent meaning) and implicit knowledge (how it is said and done, i.e., the documentary meaning).

\section{Results}

\section{Classroom interactions}

Analyses from three periods of the teaching unit, which lasted eight 90-min periods, are presented (see Table 1). These sequences were selected for two reasons. First, according to the focus of the study and the research question, teleological explanations should be observable in the sequence. Second, the sequences should represent different stages of the unit. The introductory period sets the ground for the unit and is hence particularly important for the interpretations. The fourth period is in the middle of the unit, and in the seventh period, the interactions in the classroom show the understanding of evolution at the end of the unit. As teleology is explicitly discussed, 
Table 1 Content of teaching unit

Period $1^{\text {a: }}$ presentation of imaginary fish adapted to their environment; biodiversity in marine ecosystems; overview of evolution unit

Period 2: time scales of evolution: timeline from the origin of life until today

Period 3: comparison of vertebrate classes: amphibians and reptiles

Period $4^{\mathrm{a}}$ : evolution of whales: from the shore to the sea

Period 5: Darwin's voyage and evolutionary theory: documentary

Period 6: evolution of camouflage in a colored habitat: model simulation

Period $7^{\text {a. }}$ goal-directedness of evolution: discussion

Period 8: speciation through diversifying selection: evolution of giraffes and okapis

a Sequences of these periods are presented in the results section

this period sums up the previous teaching and learning progress.

In the results section, first, the main findings are summarized, and second, detailed analyses of the sequences are presented to illustrate these findings. Within the different sequences of the teaching unit, we find a rich variety of teleological and anthropomorphic explanations: intentional design of an organism, external agency, references to human-made artifacts, active adaptation processes of organisms, perfect adaptation, internal needs of individuals, inheritance of acquired traits as a result of goal-directed adaptation, and references to a personified evolution. The interaction of the teacher and the students shows that the teaching habitus allows for the continuous reproduction and enforcement of such teleological and anthropomorphic explanations of evolution. The teaching habitus is characterized by openness and ambiguity; i.e., tasks and questions propose a compatibility of scientific and teleological explanations, the teacher validates and elaborates on the students' teleological explanations, and he does not reject them. Furthermore, the teaching habitus can be described as appreciating. The teacher highly values the students' contributions and responses, which the students also understand as a positive evaluation of their teleological explanations. These interactions and aspects of the teaching habitus can be reconstructed across the unit in a homologous way. In the first period, which sets the ground for the teaching unit, the teacher asks the students to draw an imaginary fish that is best adapted to its environment. This requires the combination of design elements and biological knowledge about the affordances of the habitat. In the fourth period, causal reasoning for the evolution of whales is combined with emotional experiences and deliberate decisions related to individual behavior. In the seventh period, the teacher asks students to prove or disprove the phrase "Evolution has no goal!" Despite a list of concepts relevant to evolutionary processes, which the students had copied from the chalkboard into their folders, and six preceding 90-min periods, the students explicitly considered evolution goal-directed. In these periods, the students continuously elaborated on teleological explanations by introducing traits with reference to human-made artifacts, deliberate decisions of individuals that are communicated to the offspring in direct speech, or a personification of evolution. From the students' reactions to the teacher's tasks, questions and evaluations, we can conclude that they interpreted the teacher's openness and ambiguity as an encouragement to elaborate the teleological explanation or as a validation of their answer.

\section{Period 1: presentation of imaginary fish adapted to their environment $^{3}$}

At the beginning of the period, the teacher asks the students to repeat the task of the homework.

Teacher: We haven't done biology for quite a while now. So, you'll have to help me quickly: what homework did you have to do for today? 0:12:07

Paul: $\quad$ Uhm. We had to paint an imaginary fish and make a poster about it. 0:12:18

Celine: It was supposed to be a fish that is perfectly adapted to its environment. 0:12:32

Anne: We also had to annotate the fish. 0:12:38

Teacher: Who wants to present their imaginary fish? I can't wait. Really. (3) We have time, we'll listen to as many as possible. 0:12:52

The task assigned by the teacher to draw an imaginary fish involves designing an animal perfectly adapted to its environment. The process requires deliberately attributing traits in a teleological way. In addition, the use of the word "paint" suggests an

\footnotetext{
${ }^{3}$ All interpretations are based on the German transcripts. A selection of transcripts was then translated for publication. Transcription rules: Word is emphasized, ${ }^{\circ}$ word ${ }^{\circ}$ is said quietly, ( ) is inaudible, (word) is difficult to understand, (3) is a pause of three seconds, $L$ is an overlap of two speakers, ((nonverbal sound)).
} 
artistic task rather than a scientific drawing, relating the task more to a child's activity than to scientific processes. While the task is teleological, it involves simultaneously taking into account biological knowledge of the animal's habitat. Consequently, through this task, the teacher proposes a compatibility between biology and imagination. The way the teacher asks the students to present their drawings, e.g., his excitement and the allowance of ample time for the students' presentations, as well as the fact that the students come to the front of the class for their presentation, reveal his high appreciation of the students' contributions. In summary, the teacher's framework of orientation at the beginning of the teaching unit, and thus his teaching habitus, are characterized by appreciation of the students' contributions as well as ambiguity regarding the compatibility between scientific and teleological explanations.

After two presentations, the teacher asks Nils to present his fish:

\section{Teacher: Nils please! 0:20:17}

Nils: $\quad$ So, my fish is a shark and is called cuttingknife shark, because it has knife-like metal deposits on his fins. It has dark blue scales on his body, and on the dorsal fin the scales are a lighter blue (just a little bit). From below you can only see its bright fin in the dark water and that confuses you a bit. The caudal fin is slightly darker at the front and lighter at the back, which also has to do with light reflections. The fins are self-sharpening highly concentrated metal deposits that work like knives. It can then swim through shoals of fish and split the fish. ((several students laugh)) After that, it ((several students laugh)) swims through the shoal again and eats them. ((several students laugh)) It also has again ((several students laugh)), which benefits it, because it can swim very fast. And it can always keep his eye free, if anything comes up against it. It is very streamlined and that helps it swim very fast. 0:21:45

\section{$[\ldots]$}

Nils: With these two characteristics and its streamlined appearance it has really adapted perfectly to its environment. 0:23:45

((Several knock on their tables.)) 0:23:45-0:23:51

Nils' presentation can be interpreted as an elaboration of the compatibility of scientific and teleological explanations. His explanations include detailed characteristics of real fish, such as the color of the fins and scales as well as the streamlined shape of the body. At the same time, the accumulation of metal in its fins and the knife-like sharpness, which have the function of killing its prey, are aspects of Nils' imagination. Characteristics of an everyday artifact, a knife, are transferred into the biological world. He describes extreme adaptations (the ability to kill all prey and the speed of $200 \mathrm{~km} / \mathrm{h}$ mentioned later in his presentation), which match his summary that the animal is "perfectly" adapted. Evolution is not presented as an ongoing process. Rather, the goal of adaptation has been reached. Moreover, the task to draw one animal proposes to focus on the level of the individual. This is elaborated by Nils as "it has really adapted perfectly to its environment". The adaptation process is described in an active way, suggesting agency. A classroom routine of mutual appreciation is performed by knocking on the tables. Subsequently, the students comment on Nils' presentation:

Nils: $\quad$ Marcel? 0:23:52

Marcel: Well, I thought it was very good and I think your picture looks a little bit like an airplane. ((several students laugh)) 0:23:56

Nils: ((several students laugh)) Indeed, most airplanes are actually covered with shark skin. Jonas? 0:24:05

Jonas: Well I thought it was a really good idea, with the metal deposits, and it was really creative. $0: 24: 14$

Nils: $\quad$ Philipp? 0:24:19

Philipp: I find it a bit brutal that it cuts up his victims, or something like that, and maybe what one could have done with the fins would be that the bones were formed in such a way that they became sharp. 0:24:31

Nils: $\quad$ No. 0:24:31

Nils: Bones are (actually) not as sharp as metal deposits. 0:24:34 [...]

Teacher: Just some feedback from me, a very good presentation, it was clear that you're an expert on fins [...] You communicated with the audience and mentioned many points on how the fish survives and catches its prey. Wonderful Nils, excellent. 0:26:03

\section{$[\ldots]$}

Teacher: I think we can carry on doing this. I've looked over your shoulder. The imaginary fish that you've drawn are very creative, and you've made annotation about which characteristics 
make them particularly suitable for survival. $0: 33: 17$

The students comment on Nils' presentation in an appreciating way. The teleological orientation is elaborated by the other students through their reference to constructing artifacts, such as an airplane. Valuing the students' creativity as part of the process of designing an animal supports the teleological orientation of the teacher. The word "idea" alludes to conscious and deliberate planning during the drawing process. The mechanism in which the fins could be designed is discussed in an antithetical way, although the notion of design and agency is not challenged in the interactions but rather confirmed by using the words "what one could have done". This interaction suggests a common teleological orientation of the students. Similar to the students and homologous to his introduction, the teacher values Nils' presentation and later his creativity without further reacting to any of the teleological explanations. Again, a compatibility of design-teleology and scientific aspects can be reconstructed.

In a later phase of the introductory period, the teacher asks what this activity has to do with the topic of the unit on evolution. This is a central situation because it shows how the students relate to the ambiguous teaching habitus:

Nils: This has to do with our topic, because we have now painted our own fish and they are for the most part also perfectly adapted to their environment. Evolution also means that fish or just about all living things evolve so that they are well adapted to their environment. One can now say that there is no orangutan in the Arctic; there would be no point for him to live there, he'd rather live in the rainforest. 0:05:44

Nils parallels the design-based drawing of animals with evolution and thus connects the first activity of the unit with evolutionary principles. Using the conjunction "so that", Nils describes evolution in a goaldirected way aiming at adaptation. In a homologous way, this explanation is made plausible by looking at the individual level, suggesting that not being adapted to the environment would not make any sense. Directly after this quote, the teacher introduces a new task and ends the discussion of this activity.

In conclusion, the ambiguity in the teacher's interactions with the students regarding the relation of teleology and science as well as the teacher's appreciation of students' contributions can be reconstructed as part of the teaching habitus. Although the degree of imaginary and scientific elements varies between the different presentations of the students, the compatibility of teleology and evolution can be reconstructed as the students' common orientation.

\section{Period 4: evolution of whales: from the shore to the sea}

In the fourth period, the teacher presents a picture of a reconstruction of Ambulocetus natans, an ancestor of today's whales, which presumably lived both ashore and underwater, and discusses how whales as marine mammals evolved from land-living ancestors.

Teacher: This lesson is really about whales. We're going to try and reconstruct how scientists actually found out that this evolutionary path from land to water, which is exemplified by whales, today's whales, really happened. Here is a small (2) picture about that. 0:35:41

$[\ldots]$

Teacher: What reasons could there be for a mammal to suddenly look for another habitat? The mammal was very happy on land. 0:42:52

At the level of biological content, the teacher introduces the question for this period, the reasons for the evolution from land-living mammals to whales living under the sea. The way that the teacher introduces this question, however, is ambiguous. On the one hand, he alludes to scientific discovery, reconstruction and causal reasoning. On the other hand, he formulates the question in an anthropomorphic way, assigning feelings and deliberate action to an individual. Evolution is presented as the result of individual behavior. The change in habitat seems paradoxical considering the stipulated positive emotional experience on land.

In response to the teacher's question about the animal's reasons to look for another habitat, the students provide suggestions such as a lack of food and fear of stronger animals and predators. Nils elaborates on the latter aspect:

Nils: It may be that a group of animals just went into the water because maybe these were weaker animals, who could not compete with the stronger animals on land, of the same species, and who passed on to their young when giving birth: you should stay in the water, there's plenty of food and you're safe here. And maybe it eventually came about that the group that lived on land, of that species, perhaps then went extinct due to predators or other things, climate change, even an ice age. 0:47:11 
Teacher: Fantastic idea, great. I would like you to repeat a sentence that I didn't hear properly. You said that the weaker group of animals then went into the water because of possible predators outside the water. 0:47:25

Nils: No, it was that the weaker animals of the species went into the water since they didn't have enough food because of the stronger animals on land, and maybe they were attacked by those, at the very least they went into the water, and they said: we can also find food here, and when they had babies there, they said to the babies: stay in the water, you do not have to go ashore because it's good here too. 0:47:54

Teacher: Okay; I wanted to talk about that, I didn't understand that so well before, you said they told the young animals. 0:48:01

Nils: $\quad$ They instinctively passed it on $L$ they were

Teacher:

Nils:

L Aha. 0:48:02

probably able to communicate. Whales and dolphins are actually quite intelligent animals. 0:48:08

Nils explains the evolutionary process as a reaction of weaker groups of animals to stronger groups ashore and a final extinction of the land-living group. The way that he explains this process, e.g., the deliberate reaction to environmental factors and the use of direct speech of the parental generation with their offspring, elaborates on the anthropomorphic and teleological orientation introduced in the teacher's initial presentation of the task. At the same time, Nils includes many aspects of biological knowledge in his explanation: differential evolution of subgroups within a population, intraspecific competition, struggle for life, and extinction of species. However, the way in which he integrates these aspects into the explanation is teleological and anthropomorphic.

In his reaction to Nils' explanation, the teacher shows high appreciation and thus validates Nils' anthropomorphic and teleological answer. When the teacher responds to Nils for the second time in the classroom transcript cited above, he asks Nils to be more specific about his idea that the whales talked to each other. On the one hand, this requires repetition and elaboration; on the other hand, the teacher provides the opportunity for Nils to reject the idea that animals can communicate about their evolution. Nils interprets this ambiguous utterance of the teacher as a request for elaboration and expands his anthropomorphic explanation.

Directly following this interaction, the teacher shifts the focus without further evaluating Nils' answer:
Teacher: Marcel contributed a new word in the last lesson, namely DNA. What other word did we choose for that, a normal simple word? How did we want to remember it? 0:48:20

Carl: $\quad$ Genetic information. 0:48:22

Teacher: Genetic information. Can you maybe integrate this? 0:48:25

Nils: That their genetic information predisposes them, that they should just stay in the water, because it's actually not so bad in the water. 0:00:04 $4^{4}$

Teacher: Genetic information is simply transferred. So. Let's start by making a point. 0:00:09

The teacher asks Nils to include the biological aspect of genetic information in his explanation. Nils then embeds genetic information in his previous anthropomorphic explanation. The communication from one generation to the next is replaced by passing on genetic information. Consequently, the mode of passing on information is changed. Nevertheless, this explanation remains teleological and anthropomorphic because the reason for this behavior, which is again paralleled with evolution, is a deliberate evaluation of the new habitat as "not so bad". The transition to the next topic of the period has the function to conclude and validate the previous interaction. Homologous to many other sequences within this unit and other units of the same type of teacher-student interactions, the teacher positively evaluates the embedment of scientific terms in a teleological and anthropomorphic explanation.

\section{Period 7: goal-directedness of evolution ${ }^{5}$}

Close to the end of the unit on evolution, the teacher initiates a discussion about the phrase "Evolution has no goal!", which he writes on the board. The task for the students is as follows:

Teacher: [...] Use the picture on the board again, the one you used for the homework, and try to critically question the headline here on the board and try to confirm or say, that's right, because... or that's not true, because, (2) try to prove it or disprove it with the help of the picture on the board. [...] 0:36:10

In the period prior to discussing the phrase "Evolution has no goal!", the teacher had written the evolutionary mechanisms on the board, which the students

\footnotetext{
${ }^{4}$ Change of timecode from 0:48:30 (first video file) to 0:00:00 (second video file).

${ }^{5}$ Parts of the transcript of period 7 and the subsequent interpretations were published in German by Martens and Gresch (2018).
} 
had copied. Five points had been listed: overproduction, variation, competition, heredity/reproductive success, and selection. In relation to variation, mutations had been introduced as sudden changes in genetic information. When the teacher asks if evolution has goals, the teacher makes a reference to these mechanisms and thus proposes the importance of scientific explanations. From these notes on the board and in the students' folders, it can be concluded that evolution is not goal-directed, and the statement should be evaluated as correct. The task to "prove it or disprove" the phrase explicitly allows the possibility that this sentence may be wrong. Through this openness of the task, goal-directedness of evolution becomes a possible explanation. The subsequent sequence will present how the students interpret this open task. It can be seen that the goal-directedness of evolution is indeed not challenged by the students but instead elaborated on. The teacher elaborates on the students' teleological explanations and does not reject them. This passage of a whole-class discussion follows a phase of small group discussions.

Nadine: Uhm, well (4) I think I, we wrote down a sentence on that, which I now think, fits quite well. Evolution has a goal, somehow, there is a goal in every generation, for example something adapted to a natural enemy, something camouflaged itself well, but the enemies also evolve and in this generation it was the goal to adapt to that specific thing, and in the next generation it carries on. 0:00:21

Teacher: So, evolution is planned, it plans and then thinks and says (4) I must have a thicker skin when it gets too cold. 0:00:42

Nadine: Exactly, because winters are getting colder and colder now, and yes, then, if you live outside, you have to be better adapted to survive the winter. 0:00:54

Teacher: And as a result, you get a thicker skin? 0:00:55

Nadine: Exactly, then you look for more food during the rest of the year, squirrels, for example.

Teacher: Jonas, pay attention. 0:01:00

Nadine: Just as an example, they look for food throughout the whole year so that they can survive in the winter. 0:01:11

Teacher: We're doing something very important here for you to really understand evolution. That's why we're discussing it here... Sophie, what is your opinion on what Nadine just said? Sophie and Nina also have something to contribute. 0:01:23
Sophie: I find it quite obvious, (but) also why does evolution do that? I mean, it could somehow change the animals differently, to be better adapted to their current habitat. And why does evolution regulate everything so that it works at all. (2) I mean you then immediately ask yourself what evolution actually is. 0:01:45

Teacher: What is evolution then, in your opinion? 0:01:48

Sophie: $\quad$ Nobody really knows why nature works the way it does; we don't even know why life exists at all. 0:01:48

Teacher: That's right, it's a question of origin. Even biologists argue about why life actually exists, even they don't really know, but evolution is quite well understood. 0:02:09

Sophie: $\quad$ So, what is it? 0:02:11

Teacher: That's what we're doing here. I'll let you think about it for a while. I don't think I should just always explain it to you, you should understand it. 0:02:22 [...]

Several students suggest that evolution is goal-directed. Nadine presents an anthropomorphic explanation in which evolution becomes a subject and an active agent. Camouflage is the result of an active process of adaptation, which is a uniform reaction of the entire population. Homologous to previous sequences, an ambiguous teaching habitus can be reconstructed in the interactions. Despite the reference to evolutionary mechanisms in the beginning of the task, the teacher now supports Nadine's anthropomorphic and teleological explanation and suggests a deliberate planning process of a personified evolution. He enforces this idea through the use of direct speech in the first person and a reference to needbased adaptations that result in thick skin. Subsequently, Nadine validates his elaboration. As a consequence, we can conclude that she interprets the teacher's utterance not as an exaggeration, provocation or challenge but as a correct statement. Nadine makes this notion plausible by paralleling morphological adaptation and behavior, here, the search for food before the cold winter. Consequently, the teacher's response is considered a positive evaluation.

Sophie validates Nadine's orientation, and thus, an anthropomorphic understanding and personification of evolution are perpetuated in the interactions. For the teacher, it is important that students discover scientific knowledge in whole-class discussions. He positions himself as knowledgeable, and it becomes clear that the students have not yet discovered the relevant knowledge. 
Overall, the whole-class discussion on goal-directedness lasts more than 18 minutes. Subsequently, the teacher concludes and closes the period.

Teacher: Very good. (2) At the moment it's a bit difficult for me to represent what you've said as text on the chalkboard because I've got the picture that you should use as a basis for learning in my head. (4) Let's use that as a representation on the chalkboard. To start with, anyway, the fact of the matter is that evolution has no goal. You had a lovely discussion about that already. Different opinions have shown that very clearly. Some of you. 0:12:18

Philipp: Isn't evolution a type of vicious circle? (which has a goal, but also doesn't) 0:12:24

Teacher: Some of you supported this, and why does evolution not have a goal? Sometimes it's really difficult to understand, but if you continue to argue, as you did in the homework assignment, that many or that animals, that the offspring all have variations, and that everything is a random process, then evolution has no purpose. 0:12:53

Philipp: $\quad{ }^{\circ}$ But not everything is a coincidence. ${ }^{\circ} 0: 12: 54$

Teacher: Natural selection then chooses, which makes it a directed process, but there's still no goal. 0:13:07

The teacher validates the students' contributions and appreciates their participation. Nevertheless, he states that the students' comments have not yet met his expectations according to scientific and curricular norms. The students' conceptions are evaluated as deficient and as an individual problem. Therefore, the teacher's evaluation of the students' discussion is ambiguous, as he both appreciates the students' comments and characterizes them as insufficient. Moreover, he summarizes the discussion by saying the opposite of what the students said. The teacher resolves this conflict between his expectations (rejection of goal-directedness according to evolutionary principles) and the outcome of the discussion (acceptance of goal-directedness) by writing a summary of evolutionary principles on the chalkboard. Whereas the phrase "Evolution has no goal!" was introduced as an open-ended question, it is now constructed as a fact. However, the only correct option - that evolution is not goal-directed - has not been discovered by the students. Despite the positioning of the teacher and the confirmation that evolution is indeed not goal-directed, the summary remains ambiguous, as natural selection is presented as an agent in an anthropomorphic way.

\section{Interview}

In the interview, the teacher explicitly introduces two norms of teaching: the educational norm of student motivation and the scientific norm of adequate evolutionary explanations. While the first norm legitimizes teleological explanations, e.g., when the teacher describes the teleological design of an animal as motivating, the teacher associates the second norm with a rejection of teleological explanations as incorrect, e.g., in an exam. In the post hoc rationalization in the interview after the teaching unit, the conflict between these two norms is resolved by considering teleological explanations a valuable student contribution, and these explanations are then discussed in terms of transforming teleological explanations into scientifically valid explanations of evolution. In conclusion, the teacher describes a successful conceptual development as a result of planned teaching processes.

These findings will be illustrated with passages from the interview. At the beginning of the interview, the interviewer hands over a paper with four student quotes from this grade seven course plus one picture of an imaginary fish drawn by a student in the first period. The interviewer asks the teacher to read the quotes first (see words in italics in the interview transcript) and then to say anything that comes to his mind.

T ${ }^{6}$ : Okay, I'll start with a pupil from middle school, from the seventh grade: My imaginary fish is called Algitus. It lives in deeper seaweed waters, in the salty depths. It's a predatory fish. It sports a green pattern, which helps it camouflage itself within its environment. To make sure that it also keeps sight of things during the night, it has a nightvision feature. This description is complemented with a highly creative drawing of a fish. The idea behind this teaching unit was to inspire the imagination of the pupils, which in turn helps to motivate them. That was the basic idea behind this for me. However, I was also well aware that this would produce exactly this kind of result, this reasoning behind ensuring that it can also see at night. I'm not really sure how we actually discussed these words during class later on. In the end, this revolves around something very goal-directed. I think that we've talked about this topic every so often during class as well, that goal-directed organs or matters, or goal-directed reasonings, don't really hold up when discussing evolution. And that was exactly the idea, that on top of the

\footnotetext{
${ }^{6} \mathrm{~T}$ : Teacher; words in italics are read aloud from the paper given by the researcher.
} 
imagination, on top of the exchange and variability, which directly became visible to the pupils, which they then ultimately generate themselves by drawing various types of fish. The underlying idea was that they formulate something of this nature themselves, to form a foundation for discussions, (3) exactly in line with this goal-directedness. [...]

After reading the student's quote aloud, the teacher makes a positive comment on the drawing of the student by emphasizing his creativity. The teacher then immediately changes into a mode of justification, explaining the rationale behind the planning process for the unit. At an explicit level, he states that imaginative elements are used as a means for student motivation; i.e., student motivation is explicated as a teaching norm. The word "however" introduces a contrast between the motivational aspect and the result of the activity, i.e., the student's explanation, which the teacher describes as teleological. Later in this passage, the teacher evaluates teleological explanations as incompatible with the scientific norm of evolutionary principles. In the interview, it becomes apparent that these two different norms coexist in conflicting ways. Regarding teleology, the norm of student motivation offers the opportunity for the teleological design of animals, while a scientific norm of evolutionary principles is linked with the rejection of teleology. However, the underlying conflict is resolved by combining the motivational aspect of imaginary drawings with scientific learning progress. The teacher states that the variability of different fish (an element of evolutionary mechanisms) is produced through the students' drawings (which were made in a teleological way).

In a mode of justification, the teacher states that he had been aware of the teleological explanations and that these served as a "foundation for discussions". Inconsistencies between the scientific norm and the teleological student quotes, which are a product of the teaching approach, are presented as a result of conscious planning showing the teacher's underlying framework of orientation of presenting himself as a reflective and consistently acting teacher. However, inconsistencies between the scientific norm and the teleological explanations are not resolved within the activity but instead postponed to a later discussion. Talking about the teleological explanations in the classroom is presented as an appropriate way to learn about scientific explanations. However, during the entire interview, the teacher does not elaborate on the process of such a discussion.

Subsequently, the teacher reads aloud the second and third student quotes of the seventh-grade course on evolution:
T: Discussion on the topic of evolution has no goal, grade seven. I believe that this is incorrect, because creatures do evolve in a goal-directed manner. Take the whale, for example, which didn't evolve into an aquatic animal just like that. It evolved with the goal of surviving in water. (8) A wonderful statement, exactly because it is perfect for further teaching. And this concept also demonstrates that there is good reason to talk about just these kinds of things. [...]

T: Question to the pupil: In other words, evolution follows a plan; evolution thinks and says I need to have a thicker coat when it gets too cold outside? ((laughter)) Answer: Exactly, because the winters are now getting colder each year as well, and one needs to adapt better when living outside in order to survive the winter. (2) Okay, of course I'll get out the red pencil whenever this statement or the previous statement is made in a class test: teleological. But when this point is made during class, I'm always thankful, because it also offers starting points for a discussion on how evolution has actually been taking place, and that evolution in the end does not have any goal. [...]

Homologous to the previous passage, the teacher simultaneously appreciates the students' explanations and evaluates them as incorrect. The two norms of student participation and correct scientific explanations can be reconstructed. The conflict of these two norms is resolved by distinguishing between the role of teleological explanations in whole-class conversations and in summative assessment. Although the students' teleological explanations allow the teacher to start with his teaching approach of discussing statements and although teleological explanations are described as fruitful, the final aim of the teaching approach is to avoid them. Furthermore, classroom discussions are constructed as the means for transforming students' teleological explanations into scientifically correct explanations.

Later in the interview, the conflicting norms are elaborated on:

$\mathrm{T}$ : It continuously becomes apparent, also after discussing the subject various times, that this trap keeps popping up, regardless of whether this concerns the seventh grade or the high school classes, that pupils tend to reason in a goal-directed manner using words such as because, so that, in order $\underline{\text { to. }}$ When asked, the pupils then manage to define their thoughts more clearly after all, but they struggle to express these ideas in a more passive manner, 
that is, not teleologically. [...]

$\mathrm{T}$ : If the students are motivated, they manage to pick this up quickly, and start to - I'm talking about the seventh grade here - feel like discussing this. In doing so, they not only use the example of fish, they talk about dinosaurs, there really are different motivational aspects which help get the pupils motivated. This is delightful for teachers, because the pupils are really involved in class. And then it's about having them express this in technical terms - this was in grade seven - they did well they reasoned very well in the end, following Darwin.

In the last section, the two norms are further explicated. The norm of student motivation is equated with student participation and student learning. The scientific norm involves correct language use. Teleological explanations are described as obstacles to learning evolution and as resistant. Overall, the evolution unit is constructed as successful, as indicated both by reasoning according to Darwin's evolutionary theory and by student motivation. This shows the teacher's framework of orientation of presenting himself as a reflective and consistently acting teacher.

\section{Discussion}

Regarding the first research question, how the teacher and the students situationally address teleology across a teaching unit on evolution, the results of the video-based analyses show how an ambiguous teaching habitus may allow for not only a reproduction but also an enforcement of teleological explanations. The tasks of the teacher, such as the design of an imaginary animal perfectly adapted to its environment and the combination of causal reasoning about the evolution of a species with emotional experiences and the individual behavior of an animal, are characterized by a combination of teleological and scientific elements. The teacher's reactions to the students' responses lead students to elaborate on their teleological explanations, which the teacher eventually validates. In the final task at the end of the unit, the students explicitly discuss whether evolution is goal-directed. This task reveals that the students not only use teleological formulations but also provide many arguments showing their teleological understanding of evolutionary processes. This outcome is plausible considering the ambiguity of previous tasks in the unit and the teacher's continuous validation of teleological explanations.

This type of ambiguous teaching practice is not restricted to the teaching sequences analyzed in this paper; it can also be found in grade 12 high school classes (Gresch and Martens 2019), which suggests that the presented interactions can also be observed in other classes taught by different teachers. Although there is some evidence that teleological explanations are more frequent at a younger age (Kelemen 1999; Zohar and Ginossar 1998), the teaching practices in the presented seventh-grade unit are comparable to similar types of teaching practices in high school classes. In contrast, teachers of a different type of teaching habitus (Gresch and Martens 2019) reject teleological explanations throughout the unit. Classroom interactions are structured by a polarization of correct student answers, scientific explanations and Darwin's evolutionary theory on the one hand and incorrect student answers, teleological explanations and Lamarck's evolutionary theory on the other hand. Consequently, the intentionality and goaldirectedness of evolution are discussed critically in these classes.

Although the final task in the presented case study has the potential to facilitate critical discussion of teleology, it can be effective if only the students have already gained relevant knowledge for this task. However, the analyses show that the students cannot provide such knowledge, and the teacher does not offer additional learning material or information that explicitly addresses the legitimacy of teleological explanations. The analyses show that the teacher's reference to evolutionary mechanisms, which had been written on the board and copied by the students in a previous period, is not sufficient for the students to provide adequate answers. Consequently, alternative approaches to explicitly address teleology need to be discussed.

In the literature on evolution education, many suggestions have been made for dealing with teleological explanations (e.g., González Galli and Meinardi 2011; Kampourakis et al. 2012a; Kampourakis and Zogza 2009; Tibell and Harms 2017). Many approaches demand "explicit teaching focusing on these topics" (Zohar and Ginossar 1998, 693), enhancing the ability to "talk in two languages, a scientific and a colloquial one" (Kattmann 2008, 8) or "developing students' metacognitive skills" (González Galli and Meinardi 2011, 149, emphasis in original; cf. González Galli et al. 2020). These considerations acknowledge the empirical findings that student conceptions and scientific conceptions coexist and need to be applied in a suitable context (Taber 2017; Wiser and Amin 2001; Martens and Gresch 2018). In the final discussion of the unit, the students explicitly demonstrate their understanding of goal-directedness in the context of evolution on an abstract level. However, with reference to the definition of metacognition by Flavell $(1976,232)$ as “one's knowledge concerning one's own cognitive processes and products," fostering metacognitive skills requires a more systematic focus on students' 
own cognition. Two potential aspects are derived from research on metacognition and applied to the research field on student conceptions: self-assessment of one's conceptions and conditional knowledge of when and why to apply these concepts. In other research fields, self-assessment has been shown to lead to higher performance (Andrade and Valtcheva 2009; Brown and Harris 2013). A self-assessment task to compare and contrast one's own explanation with types of explanations in the literature can be an approach to reflect upon one's cognition. Fostering the acquisition of conditional knowledge (Schraw et al. 2006; cf. Pintrich 2002) may help students differentiate between contexts in which teleological explanations are appropriate and contexts in which teleological explanations are inappropriate. While teleological explanations are valid in everyday interactions, certain types of teleology are incompatible with evolutionary principles. Examining the scientific context requires analyzing which forms of teleology are acceptable and which are not. While reference to the utility of a trait in the process of selection is legitimate, the appearance of inheritable variants due to the purpose of adaptation, a predetermined direction of evolution as a whole, reference to intentionality and design-based explanations are not (González Galli et al., 2020; Kampourakis, 2020). Moreover, such metacognitive conditional knowledge would involve considering that formulations are often ambiguous; i.e., words may have different meanings in different contexts (cf. Rector et al. 2013 for different types of lexical ambiguity). Furthermore, students should be aware that in a scientific context, scientists may use metaphorical language and acknowledge that they may be "breaking the rules" of scientific language use, as stated by Lemke (1990, p. 134) and Taber and Watts (1996).

Another important approach for dealing with teleology is addressing the incompatibility of randomness and teleological adaptions (Kampourakis and Zogza 2009; Tibell and Harms 2017). Introducing randomness as a threshold concept involves focusing on genetic variations of individuals in a population (e.g., mutations, recombination). Activities that involve designing animals and explaining the evolution of species based on the preferences of individual animals neglect such random variation. A lack of understanding of the concept of randomness may lead to teleological explanations (Tibell and Harms 2017), and inducing a conceptual conflict through the concept of randomness may challenge teleological explanations (Kampourakis and Zogza 2009).

Regarding the second research question on how teaching norms and teaching practices are related, it is possible to reconstruct two conflicting norms in the interview and in classroom interactions. The teacher's explicitly stated norm of student motivation is congruent with the teaching habitus of providing activating tasks, such as the design activity, but also with high appreciation of students' participation and students' work. Furthermore, the norm of a scientifically correct explanation of evolutionary processes is explicitly stated in the interview and could also be reconstructed in the classroom practice, e.g., in the teacher's references to evolutionary mechanisms such as variation, selection and heredity on the chalkboard.

However, the reconciliation of the conflict of these two norms is presented in a different way in the interview than it can be reconstructed in the classroom interactions. In the interview, the conflict between different norms is resolved through a sequential development across the unit. Students should be motivated first and eventually construct explanations according to the scientific norm. The teacher introduces teleological explanations as a fruitful basis for discussions, and he constructs whole-class discussions as a learning opportunity for the students so that teleological explanations are transformed into scientifically acceptable explanations. Consequently, the teacher constructs the evolution unit as successful.

In contrast to the teacher's post hoc characterization in the interview, the norms remain in conflict in the classroom as a result of the ambiguous teaching habitus. Openness in the tasks and ambiguity in the discussions provide ample opportunities to elaborate on teleological explanations and to combine them with scientific explanations. Moreover, a positive validation and appreciation of students' teleological explanations and their contributions may be congruent with the norm of motivating students but is incongruent with the norm of transforming teleological explanations into scientific explanations. This becomes apparent in the discussion about the goal-directedness of evolution. The teacher eventually evaluates the outcome of the discussion as deficient and incompatible with the scientific norm. The students did not reject the goal-directedness of evolution despite the discussion, which he claims to be central to the development of student conceptions in the interview. In conclusion, the teacher seems aware in the interview that the two norms are in conflict, but he is not able to reconcile them in his teaching and is even unaware of the ambiguities in his teaching approach, which perpetuate teleological explanations.

Such a discrepancy between the teaching habitus and teaching norms is plausible from a theoretical perspective (Bohnsack 2014; Hericks et al. 2018; cf. Mansour 2013 for the relation between teachers' beliefs and practice). While institutional and pedagogical norms, such as student motivation or conceptual development, are understood as exterior expectations, these need not be internalized in a way that they become part of the 
teacher's habitus. From the perspective of systems theory (Luhmann 2002), it is also plausible that classroom interaction does not necessarily proceed according to intentional planning processes, as in the interview. Learning processes cannot be determined in a technological way, and interaction may result in different outcomes from those expected. Therefore, the reconciliation of such norms is more complicated in complex classroom interactions. This discrepancy of norms reconstructed in this case study is also central to normative discussions in the field of biology education. While generally, the conceptual development from teleological to evolutionary explanations is one important aim of teaching (e.g., Kampourakis and Zogza 2009), student motivation, interest and empathy towards living organisms through the use of teleological and anthropomorphic explanations is also stated as a norm of teaching biology (Kattmann 2008; Zohar and Ginossar 1998). As a consequence, this discrepancy between teaching norms and teaching practice makes it important for further research not only to examine teachers' norms and beliefs in interview situations but also to reconstruct teachers' implicit knowledge in the course of action because the explicitly stated norms do not fully explain the interactions in the classroom.

Overall, these analyses provide insights into actual classroom interaction regarding the use of teleological explanations and the relation to teaching norms. However, some limitations have to be addressed. Most importantly, the analyses from this case study cannot be generalized as typical for all or the majority of evolution classes. Instead, this class was purposefully selected as part of the theoretical sampling strategy because it is an example of how teleological explanations were reproduced throughout the entire unit. Moreover, we cannot report on individual conceptual change as in studies using a pre-post design. This means that we have little information on the learning processes of the students who do not participate in the classroom discussion. Nevertheless, all whole-class talk is audible to the students, and public validations and elaborations of other students' answers presumably impact the learning processes, as they indicate the teacher's expectations. However, this individual progress cannot be inferred on the basis of video-based research designs. Furthermore, we do not have additional information on the teacher's content knowledge, pedagogical knowledge or pedagogical content knowledge. Although implicit knowledge on teaching routines could be reconstructed and contrasted with explicit teaching norms, this dimension of explicit professional knowledge could supplement the case study. Regarding the interview, one further limitation needs to be stated. The interview focused on the teacher's perspective on student conceptions and revealed general suggestions for dealing with student conceptions. However, the interview did not focus on the teacher's rationale for using the particular activities presented in this paper or the relation between this unit and previous and subsequent units.

In addition to the implications for teaching evolution in secondary education, the data and findings from this study have potential value for professional development courses and teacher education at the university level. Such transcripts and videos can be used to analyze the interactions to discuss the relation between student conceptions and scientific and curricular norms (Steinwachs and Gresch 2019, 2020). It is important for preservice teachers to learn how to diagnose student conceptions in order to develop learning sequences that take into account students' perspective and scientific concepts (Dannemann 2018). This relation between the subject content and students' perspective has been described as the antinomy of subject and person, an inherent tension in classroom interactions that cannot easily be resolved (Helsper 2016). Curricular and scientific norms may be opposed to dealing with students' individual personality and diversity. In this teaching unit, we can often observe high valuation of students' explanations and work but also distortion of the scientific content in a teleological way. When analyzing classroom interactions, preservice and in-service teachers should generally be able to notice and interpret features that are relevant to learning processes (Sherin 2007). Regarding evolution classes, teachers need to be able to recognize teleological and anthropomorphic expressions but also ambiguous formulations (cf. Rector et al. 2013) in classroom discourse. While expressions such as "all living things evolve so that they are well adapted to their environment" (Nils) or "there is a goal in every generation, for example, something adapted to a natural enemy" (Nadine) are clearly teleological, other formulations using terms, such as "adapt" or "selection", may be ambiguous; i.e., they are used as scientific terms and in everyday language and may suggest a deliberate action by a selector (Rector et al. 2013). Noticing such formulations is an essential first step in the process of understanding interactions in evolution classes. Interpreting these interactions involves examining the learning conditions for students. The task assigned by the teacher is to design well-adapted animals, and thus, it promotes teleological explanations. After uncovering the teleological and anthropomorphic basis of such tasks, alternatives for instruction can be developed, such as metacognitive tasks. Consequently, we suggest using these transcripts as rich examples of various facets of teleological and anthropomorphic explanations and analyzing the interactions in preservice teacher science education courses 
to reflect on dealing with teleological student conceptions in evolution.

Based on these findings, several directions for further research can be derived. First, it is important to conduct further comparative analyses to describe different teaching practices in middle school evolution classes. These analyses should be systematically contrasted with results from upper high school classes. Second, focusing on individual learning progress, the effect of metacognitive skills on the acquisition of knowledge regarding evolutionary principles and the development of student conceptions needs to be investigated. In particular, selfassessment and fostering conditional knowledge about different application contexts are considered promising in previous research in educational psychology. Third, the effect of professional development courses that include the analysis of such video transcripts on teaching practice needs further attention. Such a focus on professional development would involve video-based analyses of teachers' classroom practice as well as analyses of the processes within professional development courses.

\section{Acknowledgements}

The author would like to thank Prof. Dr. Marcus Hammann, Prof. Dr. Matthias Martens, the editor and the reviewers for their critical review of the manuscript and their valuable comments. Moreover, the author would also like to thank the documentary method interpretation groups in Frankfurt am Main and Münster, in particular Prof. Dr. Barbara Asbrand, for the discussion of the interpretations.

\section{Authors' contributions}

The author collected the data (supported by a student employed by the University of Münster), analyzed the videos, interview and transcripts, and wrote the manuscript. All authors read and approved the final manuscript.

\section{Funding}

I acknowledge support from the Open Access Publication Fund of the University of Münster.

\section{Availability of data and materials}

Relevant transcripts of the classroom interaction are presented in the manuscript. Further transcripts can be received upon request to the author. The original videos cannot be published because of data privacy regulations.

\section{Competing interests}

There are no competing interests.

Received: 29 September 2019 Accepted: 14 May 2020

Published online: 29 May 2020

\section{References}

Abrams E, Southerland S. The how's and why's of biological change: how learners neglect physical mechanisms in their search for meaning. Int J Sci Educ. 2001;23(12):1271-81. https://doi.org/10.1080/0950069011 0038558.

Aldridge M, Dingwall R. Teleology on Television? European J Commun. 2003; 18(4):435-53.

Andrade $\mathrm{H}$, Valtcheva A. Promoting learning and achievement through selfassessment. Theory into Pract. 2009;48(1):12-9.
Asbrand B, Martens M. Dokumentarische Unterrichtsforschung [Documentary classroom research]. Wiesbaden, Germany: Springer VS; 2018.

Bartov H. Can students be taught to distinguish between teleological and causal explanations? J Res Sci Teach. 1978;15(6):567-72. https://doi. org/10.1002/tea.3660150619.

Bartov $\mathrm{H}$. Teaching students to understand the advantages and disadvantages of teleological and anthropomorphic statements in biology. J Res Sci Teach. 1981;18(1):79-86. https://doi.org/10.1002/tea.3660180113.

Betz N, Leffers JS, Dahlgaard Thor EE, Fux M, de Nesnera K, Tanner K, Coley JD. Cognitive construal-consistent instructor language in the undergraduate biology classroom. CBE—Life Sci Educ. 2019;18(ar63):1-16.

Bishop BA, Anderson CW. Student conceptions of natural selection and its role in evolution. J Res Sci Teach. 1990;27(5):415-27. https://doi.org/10.1002/ tea.3660270503.

Boerwinkel DJ, Waarlo AJ, Boersma K. A designer's view: the perspective of form and function. J Biol Educ. 2009;44(1):12-8. https://doi. org/10.1080/00219266.2009.9656186.

Bohnsack R. Documentary method and group discussions. In: Bohnsack R, Pfaff N, Weller W, editors. Qualitative analysis and documentary method in international educational research. Opladen, Germany: Barbara Budrich; 2010. p. 99-124.

Bohnsack R. Habitus, Norm und Identität [Habitus, norm and identity]. In: Helsper W, Kramer R-T, Thiersch S, editors. Schülerhabitus. Theoretische und empirische Analysen zum Bourdieuschen Theorem der kulturellen Passung [student habitus. Theoretical and empirical analyses to Bourdieu's theorem of cultural fit]. Wiesbaden, Germany: VS; 2014. p. 33-55.

Brown GTL, Harris LR. Student self-assessment. In: McMillan J, editor. SAGE Handbook of research on classroom assessment. Thousand Oaks: SAGE; 2013. p. 367-93.

Casler K, Kelemen D. Developmental continuity in teleo-functional explanation: reasoning about nature among Romanian Romani adults. J Cognition Develop. 2008;9(3):340-62. https://doi.org/10.1080/1524837080 2248556.

Coley JD, Tanner KD. Common origins of diverse misconceptions: cognitive principles and the development of biology thinking. CBE-Life Sci Educ. 2012;11:209-15.

Crawford BA, Zembal-Saul C, Munford D, Friedrichsen P. Confronting prospective teachers'ideas of evolution and scientific inquiry using technology and inquiry-based tasks. J Res Sci Teach. 2005;42(6):613-37. https://doi. org/10.1002/tea.20070.

Dannemann S. Rethinking lesson planning — using video vignettes as cases in e-learning scenarios. In Finlayson OE, McLoughlin E, Erduran S, Childs P, editors. Electronic proceedings of the ESERA 2017 conference. Research, practice and collaboration in science education, part 13/208. Dublin, Ireland: Dublin City University; 2018. p. 1881-1891.

destatis (2020). Schüler/-innen an allgemeinbildenden und beruflichen Schulen [students at general and vocational public schools]. https://www. destatis.de/DE/Themen/Gesellschaft-Umwelt/Bildung-Forschung-Kultu $\mathrm{r} / \mathrm{Schulen/Tabellen/allgemeinbildende-beruflicheschulen-schularten}$ -schueler.html. Accessed 01 Feb 2020.

Evans EM, Rosengren K, Lane JD, Price KLS. Encountering counterintuitive ideas: constructing a developmental learning progression for evolution understanding. In: Rosengren K, Brem SK, Evans EM, Sinatra GM, editors. Evolution challenges: Integrating research and practice in teaching and learning about evolution. New York: Oxford Univ. Press; 2012. p. 174-99.

Flavell JH. Metacognitive aspects of problem solving. In: Resnick LB, editor. The nature of intelligence. New York: Wiley; 1976. p. 231-5.

Garvin-Doxas K, Klymkowsky MW. Understanding randomness and its impact on student learning: lessons learned from building the biology concept inventory (BCI). CBE—Life Sci Educ. 2008;7(2):227-33. https://doi. org/10.1187/cbe.07-08-0063.

Glaser BG, Strauss AL. The discovery of grounded theory: Strategies for qualitative research: New York. NY: Aldine de Gruyter; 1967.

González Galli LM, Meinardi EN. The role of teleological thinking in learning the Darwinian model of evolution. Evolution. 2011;4(1):145-52. https:// doi.org/10.1007/s12052-010-0272-7.

González Galli L, Peréz G, Gómez Galindo AA. The self-regulation of teleological thinking in natural selection learning. Evolution. 2020;13:6. https://doi. org/10.1186/s12052-020-00120-0. 
Gregory TR. Understanding natural selection: essential concepts and common misconceptions. Evolution. 2009;2(2):156-75. https://doi.org/10.1007/ s12052-009-0128-1.

Gresch H. Schülervorstellungen als implizites Wissen: Genese und Umgangsweisen [Student conceptions as implicit knowledge: construction in the classroom and teaching approaches]. In Helbig K, Rheinisch B, Krüger D, editors. Biologiedidaktische Vorstellungsforschung: Zukunftsweisende Praxis [Research on student conceptions in biology education. Trendsetting Practice]. Dordrecht: Springer; 2020, p. 55-66 (in press).

Gresch H, Martens M. Teleology as a tacit dimension of teaching and learning evolution: a sociological approach to classroom interaction in science education. J Res Sci Teach. 2019;56(3):243-69.

Helsper W. Antinomien und Paradoxien im professionellen Handeln [Antonomies and paradoxes in professional actions]. In: Dick M, Marotzki W, Mieg HA, editors. Handbuch Professionsentwicklung [Handbook on professional development]. Bad Heilbrunn, Germany: Klinkhardt; 2016. p. 50-61.

Hericks U, Sotzek J, Rauschenberg A, Wittek D, Keller-Schneider M. Habitus und Normen im Berufseinstieg von Lehrer*innen-eine mehrdimensionale Typenbildung aus der Perspektive der Dokumentarischen Methode [Habitus and norms in the entry into professional life of teachers-a multidimensional development of types from the perspective of the documentary method]. Zeitschrift für interpretative Schul- und Unterrichtsforschung. 2018;7:65-80.

Jensen MS, Finley FN. Changes in students' understanding of evolution resulting from different curricular and instructional strategies. J Res Sci Teach. 1996;33(8):879-900.

Jördens J, Asshoff R, Kullmann H, Hammann M. Providing vertical coherence in explanations and promoting reasoning across levels of biological organization when teaching evolution. Int J Sci Educ. 2016;38(6):960-92. https://doi.org/10.1080/09500693.2016.1174790.

Kampourakis K. Understanding evolution. Cambridge: Cambridge University Press; 2014.

Kampourakis K. Students'"teleological misconceptions" in evolution education: why the underlying design stance, not teleology per se, is the problem. Evolution. 2020;13:1. https://doi.org/10.1186/s12052-019-0116-z.

Kampourakis K, Zogza V. Students' intuitive explanations of the causes of homologies and adaptations. Sci Educ. 2008;17(1):27-47. https://doi. org/10.1007/s11191-007-9075-9.

Kampourakis K, Zogza V. Preliminary evolutionary explanations: a basic framework for conceptual change and explanatory coherence in evolution. Sci Educ. 2009;18:1313-40.

Kampourakis K, Palaiokrassa E, Papadopoulou M, Pavlidi V, Argyropoulou M. Children's intuitive teleology: shifting the focus of evolution education research. Evolution. 2012a;5(2):279-91. https://doi.org/10.1007/s1205 2-012-0393-2

Kampourakis K, Pavlidi V, Papadopoulou M, Palaiokrassa E. Children's teleological intuitions: what kind of explanations do 7-8 year olds give for the features of organisms, artifacts and natural objects? Res Sci Educ. 2012b;42(4):651-71. https://doi.org/10.1007/s11165-011-9219-4.

Kattmann U. Learning biology by means of anthropomorphic conceptions? In: Hammann M, Reiss M, Boulter C, Tunnicliffe SD, editors. Biology in context. London: Institute of Education; 2008. p. 7-17.

Kelemen D. Why are rocks pointy? Children's preference for teleological explanations of the natural world. Dev Psychol. 1999;35(6):1440-52.

Kelemen D. Teleological minds: How natural intuitions about agency and purpose influence learning about evolution. In: Rosengren K, Evans EM, editors. Evolution challenges: integrating research and practice in teaching and learning about evolution. Oxford: Oxford Univ Press; 2012. p. 66-92.

Kelemen D, Rosset E. The human function compunction: teleological explanation in adults. Cognition. 2009;111(1):138-43. https://doi.org/10.1016/j. cognition.2009.01.001.

Kelemen D, Rottman J, Seston R. Professional physical scientists display tenacious teleological tendencies: purpose-based reasoning as a cognitive default. J Exp Psychol Gen. 2012;142(4):1074-83. https://doi.org/10.1037/ a0030399.

Konnemann C, Asshoff R, Hammann M. Insights into the diversity of attitudes concerning evolution and creation: a multidimensional approach. Sci Educ. 2016;100(4):673-705. https://doi.org/10.1002/sce.21226.

Lemke JL. Talking science: Language, learning, and values. Westport: Ablex; 1990.
Lennox JG, Kampourakis K. Biological teleology. The need for history. In: Kampourakis K, editor. The philosophy of biology. A companion for educators. Dordrecht: Springer; 2013. p. 421-54.

Luhmann N. Das Erziehungssystem der Gesellschaft [The educational system of the society] Frankfurt/Main. Germany: Suhrkamp; 2002.

Mannheim K. Essays on the sociology of knowledge. London: Routledge \& Kegan Paul; 1952.

Mansour N. Consistencies and inconsistencies between science teachers' beliefs and practices. Int J Sci Educ. 2013;35(7):1230-75. https://doi. org/10.1080/09500693.2012.743196.

Martens M, Gresch H. Ambivalente Fachlichkeiten. Die (Re)Produktion fachlicher Vorstellungen im Biologieunterricht [Ambiguity of subject matter. The (re-)production of student conceptions in biology lessons]. In Martens M, Rabenstein K, Bräu K, Fetzer M, Gresch H, Hardy I, Schelle C, editors. Konstruktionen von Fachlichkeit: Ansätze, Erträge und Diskussionen in der empirischen Unterrichtsforschung [Constructions of subject matter: approaches, returns and discussions in empirical classroom research] Bad Heilbrunn, Germany: Klinkhardt. 2018; p. 275-288.

Mayr E. Cause and effect in biology. Kinds of causes, predictability, and teleology are viewed by a practicing biologist. Science. 1961;134:1501-6.

Ministerium für Schule und Weiterbildung des Landes Nordrhein-Westfalen [Ministry for schools and professional development of the State of North Rhine-Westphalia]. Kernlehrplan für das Gymnasium-Sekundarstufe I in Nordrhein-Westfalen. Biologie [Curriculum for the Gymnasium. Lower secondary education in North Rhine-Westphalia. Biology]. Frechen: Ritterbach; 2008.

Nehm RH, Reilly L. Biology majors'knowledge and misconceptions of natural selection. Bioscience. 2007;57(3):263-72. https://doi.org/10.1641/B5703 11.

Nehm RH, Ridgway J. What do experts and novices "see" in evolutionary problems? Evolution. 2011:4(4):666-79. https://doi.org/10.1007/s1205 2-011-0369-7.

Nehm RH, Schonfeld IS. Does increasing biology teacher knowledge of evolution and the nature of science lead to greater preference for the teaching of evolution in schools? J Sci Teacher Educ. 2007;18(5):699-723. https:// doi.org/10.1007/s10972-007-9062-7.

Nehm RH, Schonfeld IS. Measuring knowledge of natural selection: a comparison of the CINS, an open-response instrument, and an oral interview. J Res Sci Teach. 2008;45(10):1131-60. https://doi.org/10.1002/tea.20251.

Opfer JE, Nehm RH, Ha M. Cognitive foundations for science assessment design: knowing what students know about evolution. J Res Sci Teach. 2012;49(6):744-77. https://doi.org/10.1002/tea.21028.

Pintrich PR. The role of metacognitive knowledge in learning, teaching, and assessing. Theory Practice. 2002;41(4):219-25.

Pittendrigh C. Adaptation, natural selection, and behavior. In: Roe A, Simpson G, editors. Behavior and evolution. New Haven: Yale University Press; 1958.

Rector MA, Nehm RH, Pearl D. Learning the language of evolution: lexical ambiguity and word meaning in student explanations. Res Sci Educ. 2013:43:1107-33.

Richardson DR. A survey of students' notions of body function as teleologic or mechanistic. Am J Physiol. 1990;258(6):8-10.

Ruse M. Teleology in biology: is it a cause for concern? Trends Ecol Evol. 1989:4(2):51-4. https://doi.org/10.1016/0169-5347(89)90143-2.

Schön DA. The reflective practitioner. How professionals think in action. New York: Basic Books; 1983.

Schraw G, Crippen KJ, Hartley K. Promoting self-regulation in science education: metacognition as part of a broader perspective on learning. Res Sci Educ. 2006;36(1):111-39.

Sherin MG. The development of teachers' professional vision in video clubs. In: Goldman R, editor. Video research in the learning sciences. Mahwah N.J.: Erlbaum; 2007. p. 383-95.

Shulman L. Knowledge and teaching: foundations of the new reform. Harv Educ Rev. 1987;57(1):1-23. https://doi.org/10.17763/haer.57.1.j463w79r56 455411.

Steinwachs J, Gresch H. Umgang mit Schülervorstellungen im Evolutionsunterricht-Implizites Wissen von Lehramtsstudierenden bei der Wahrnehmung von Videovignetten. [Dealing with students' conceptions in evolution classes-implicit knowledge of pre-service teachers in the perception of video vignettes]. Zeitschrift für interpretative Schul-und Unterrichtsforschung. 2019:8:37-51. 
Steinwachs J, Gresch H. Professionalisierung der Unterrichtswahrnehmung mithilfe von Videovignetten im Themenfeld Evolution - Bearbeitung der Sachantinomie in der biologiedidaktischen Lehrerbildung [Fostering classroom vision in preservice teacher education in the field of evolution - dealing with the antinomy of person and subject matter]. In Kürten R, Greefrath G, Hammann M, editors. Komplexitätsreduktion in Lehr-LernLaboren. Innovative Lehr-Formate in der Lehrerbildung zum Umgang mit Heterogenität und Inklusion [Reduction of complexity in teachinglearning laboratories. Innovative teaching formats in teacher education to deal with heterogeneity and inclusion]. Münster, Germany: Waxmann; 2020. p. 57-78.

Taber KS. The nature of student conceptions in science. In: Taber KS, Akpan $B$, editors. Science education: An international course companion. Rotterdam: Sense Publishers; 2017. p. 119-31.

Taber KS, Watts M. The secret life of the chemical bond: students' anthropomorphic and animistic references to bonding. Int J Sci Educ. 1996;18(5):557-68. https://doi.org/10.1080/0950069960180505.

Talanquer V. Explanations and teleology in chemistry education. Int J Sci Educ. 2007;29(7):853-70. https://doi.org/10.1080/09500690601087632.

Tamir P, Zohar A. Anthropomorphism and teleology in reasoning about biological phenomena. Sci Educ. 1991;75(1):57-67. https://doi.org/10.1002/ sce. 3730750106 .
Tibell LAE, Harms U. Biological principles and threshold concepts for understanding natural selection. Sci Educ. 2017;26(7-9):953-73. https://doi. org/10.1007/s11191-017-9935-X

Trommler F, Gresch H, Hammann M. Students' reasons for preferring teleological explanations. Int J Sci Educ. 2018;40(2):159. https://doi. org/10.1080/09500693.2017.1404658.

Wiser M, Amin T."Is heat hot?" Inducing conceptual change by integrating everyday and scientific perspectives on thermal phenomena. Learn Instruct. 2001:11(4-5):331-55. https://doi.org/10.1016/S0959-4752(00)00036-0.

Zohar A, Ginossar S. Lifting the taboo regarding teleology and anthropomorphism in biology education-Heretical suggestions. Sci Educ. 1998;82(6):679-97.

\section{Publisher's Note}

Springer Nature remains neutral with regard to jurisdictional claims in published maps and institutional affiliations.
Ready to submit your research? Choose BMC and benefit from:

- fast, convenient online submission

- thorough peer review by experienced researchers in your field

- rapid publication on acceptance

- support for research data, including large and complex data types

- gold Open Access which fosters wider collaboration and increased citations

- maximum visibility for your research: over $100 \mathrm{M}$ website views per year

At BMC, research is always in progress.

Learn more biomedcentral.com/submissions 